
\title{
25 Research Soure \\ Usefulness of K-line in predicting prognosis of laminoplasty for cervical spondylotic myelopathy
}

Terumasa Ikeda ( $\nabla$ tikeda@med.kindai.ac.jp )

Kindai university faculty of medicine

Hiroshi Miyamto

Kindai University Hospital

Masao Akagi

Kindai University Hospital

Research article

Keywords: cervical spondylotic myelopathy, K-line, cervical spinal kyphosis

Posted Date: July 23rd, 2020

DOI: https://doi.org/10.21203/rs.3.rs-42579/v1

License: (c) (1) This work is licensed under a Creative Commons Attribution 4.0 International License.

Read Full License 


\section{Abstract}

Background: K-line is widely recognized as a useful index to evaluate alignment and size of the cervical ossification of the posterior longitudinal ligament (OPLL) in one parameter. The purpose of this study was to investigate that $\mathrm{K}$-line could be a tool to predict the prognosis of LP for cervical spondylotic myelopathy (CSM) as well.

Methods: Sixty-eight patients who underwent LP were enrolled. C2-7 angle, local kyphosis angle, and Kline which is the straight line connecting the midpoints of the spinal canal at C2 and C7 was evaluated on T2- weighted sagittal magnetic resonance imaging (MRI). The JOA score and the recovery rate of the JOA score were evaluated at pre-operation and at follow-up. C2/C7 angle, local kyphosis angle, the JOA score, and the recovery rate were compared between $\mathrm{K}$-line $(-)$ and $\mathrm{K}$-line $(+)$ groups.

Results: The recovery rate of K-line (+) group (50.6\%) was significantly better than that of K-line (-) (19.4\%). In K-line (-), the disc type in which the protruded disc was absorbed during the follow-up showed statistically better recovery rate $(27.6 \%)$ at follow-up compared to other K-line (-) in which anterior cord compression due to the osteophyte or the kyphotic beak was not absorbed (osseous type, $5.0 \%$ ).

Conclusion: The present study has indicated that K-line can be a factor to predict the clinical outcome of LP for CSM. In K-line (-), the disc type showed somewhat better outcomes compared to the osseous type. However, the results were not sufficient.

\section{Background}

Laminoplasty (LP) is occasionally indicated for cervical myelopathy caused by a narrow spinal canal due to spondylosis and/or ossification of the posterior longitudinal ligament (OPLL). This procedure enables sufficient decompression in multi-segmental stenotic myelopathy. The effects of decompression with LP are attributed to two mechanisms, i.e., direct posterior decompression and posterior shifting of the spinal cord from anterior compressive lesions [1-3]. However, a large anterior bulge, as with a protruded disc or OPLL, often worsens the postoperative neurological recovery rate after LP [4-6]. Cervical kyphosis may also lead to poor surgical outcomes by interfering with posterior shifting of the spinal cord $[3,8]$. Iwasaki et al. [4] reported that the neurologic outcome of LP for cervical OPLL was poor or fair in patients with occupying ratio greater than $60 \%$, hill-shaped ossification, and postoperative kyphotic change in cervical alignment.

Fujiyoshi et al. [7] developed the K-line, a straight line connecting the midpoints of the spinal canal at C2 and $\mathrm{C7}$ on plain lateral radiograph, as a new index to evaluate cervical alignment and OPLL size in one parameter, i.e., OPLL did not exceed the K-line in the K-line (+) group and did exceed the K-line in the K-line $(-)$ group.

With regard to cervical spondylotic myelopathy (CSM), Suda et al. [8] reported that the patients with local kyphosis $\geqq 13$ degrees exhibited poorer clinical outcomes than those without kyphosis due to the 
mechanisms described above. On the other hand, Chiba et al. [9] reported that several patients accompanying by cervical kyphosis obtained an acceptable clinical outcome after LP alone, probably because of the slackening of the spinal cord due to reduced multilevel disc height, which would not be compatible with cervical OPLL. Therefore, usefulness of K-line for CSM was uncertain. The purpose of the present study was to investigate whether K-line can provide a predictor of the clinical outcomes of LP for CSM.

\section{Methods}

Participants in the present study comprised Sixty-eight patients who underwent LP as decompression surgery for CSM were involved in the present study. Exclusion criteria were myelopathy caused by singlelevel disc herniation, OPLL, or a history of cervical spinal surgery, spinal tumor, trauma, and infection.

As the ethics approval, the study protocol was approved by the Institutional Review Board of Kindai University Hospital ( Control Cohort Study, No.2020-025). We conducted this study under approval of the institutional review board and informed consent was obtained from all patients.

The operative technique was previously described by Miyazaki and Kirita's method $(n=64)$ and a modification of Kurokawa's method $(n=4)$. The method of Miyazaki and Kirita was a procedure in which bilateral gutters were made and the laminae were split in the middle with a high-speed drill. The laminae were kept open with nylon sutures in the deep fascia bilaterally. The modification of Kurokawa's method was the procedure in which mid-splitting of the spinous processes was performed using a T-saw [10]. After spreading the split spinous processes, hydroxyappatite spacers were sutured as necessary between the opened spinous process at each level.

We were able to obtain follow-up results for all 68 patients (50 males and 18 females). Mean age at surgery was 60.3 years (range, 32-92 years). All patients were followed-up for 2 year or longer after surgery. Mean follow-up period was 74.2 months (Table 1). The spinal levels of decompression were from C3 to $\mathrm{C} 7$ in 47 patients, $\mathrm{C} 4$ to $\mathrm{C} 7$ in 4 patients, $\mathrm{C} 3$ to $\mathrm{C} 6$ in 8 patients, $\mathrm{C} 3$ to Th1 and $\mathrm{C} 2$ to $\mathrm{C} 7$ in 3 patients each, and C4 to C5, C3 to C5 and C4 to Th1 in 1 patient each. 
Table 1

Background characteristics of the participants

\begin{tabular}{|ll|}
\hline Characteristic & \\
\hline Age (years old) & $60.3 \pm 12.4$ \\
\hline Sex (male/female) & $50 / 18$ \\
\hline Follow-up period (months) & $74 \pm 43.5$ \\
\hline The JOA score at preoperation (points) & $9.7 \pm 2.9$ \\
\hline The JOA score at follow-up (points) & $13.0 \pm 2.6$ \\
\hline The RR (\%) of the JOA score & $45.5 \pm 28.0$ \\
\hline C2-7 angle at preoperation (degrees) & $4.1 \pm 12.5$ \\
\hline C2-7 angle at follow-up (degrees) & $6.6 \pm 14.3$ \\
\hline Data are presented as means \pm SD. & \\
\hline JOA: Japanese Orthopaedic Association & \\
\hline RR: recovery rate & \\
\hline
\end{tabular}

\section{Clinical Findings}

The Japanese Orthopaedic Association (JOA) scoring system was used to evaluate the severity of cervical myelopathy preoperativly and at the final follow-up. The recovery rate (RR) of the JOA score was calculated using the method of Hirabayashi et al. to compare preoperatively and at final follow-up JOA scores. As defined by Hirabayashi et al., RR (\%) was calculated as (postoperative JOA score preoperative JOA score) / (17- preoperative JOA score) $\times 100$.

\section{Radiological Evaluation}

C2-7 angle was measured on T2-weighted sagittal images of magnetic resonance imaging (MRI) preoperatively and at the final follow-up. In CSM patients, although C2-7 angle was positive, local kyphosis existed due to the alignment (e.g., sigmoid, reverse sigmoid, and kyphosis) in several patients. In those cases, local kyphosis angle was also measured on T2-weighted sagittal images of MRI at preoperatively and at the follow-up. The K-line was defined as the straight line connecting the midpoints of the spinal canal at $\mathrm{C} 2$ and $\mathrm{C} 7$ on midsagittal T2-weighted MRI in the present study. The patients were divided into two groups; K-line (-) and K-line (+). In the K-line (-) group, the anterior structural factors (e.,g., disc herniation, osteophyte, or kyphotic beak of the vertebra) crossed the K-line with no space between the K-line and the anterior wall of the canal. On the other hand, in the K-line (+) group, the anterior structural factors did not exceed K-line and stayed within the ventral area of K-line. 
Clinical parameters such as gender, age, preoperative JOA score, the JOA score at the follow-up, the RR of the JOA score, and radiological parameters such as preoperative C2-7 angle, C2-7 angle at the follow-up, preoperative local kyphosis angle, and the local kyphosis angle at the follow-up were compared between K-line(-) and K-line (+).

Statistical analysis was performed using Student t-test and Mann-Whitney $\mathrm{U}$ test, with $P<0.05$ considered statistically significant. Statistical analyses of data were performed with Stat Flex Ver.6 (Artech Co., Ltd., Osaka, Japan). Results were presented as means \pm SD.

\section{Results}

The mean JOA score was 9.7 points (range, 1-14 points) before surgery and 13.1 points (range, 1-17 points) at final follow-up. The Mean RR of the JOA score was $45.5 \%$. The $\mathrm{C} 2-7$ angles at preoperatively and at follow-up were $4.1 \pm 12.5$ and $6.6 \pm 14.3$ degrees respectively (Table 1 ). K-line (-) were 11 patients ( 8 male, 3 females; mean of 57.2 years old), and K-line ( + ) were 57 patients ( 42 male, 15 females; mean of 60.9 years old). The JOA score at preoperatively and at follow-up were $10.1 \pm 4.1$ and $11.6 \pm 4.1$ in Kline (-) and $9.7 \pm 2.6$ and $13.3 \pm 2.2$ in K-line $(+)$. The mean RR of JOA score were $19.4 \%$ in $\mathrm{K}$-line $(-)$ and $50.6 \%$ in K-line (+) group, representing a significant difference. With respect to radiological findings, preoperative C2-7 angle was significantly smaller in the K-line (-) group (-10.1 \pm 9.0 degrees) than in the Kline (+) group (6.8 \pm 11.2 degrees). The C2-7 angle at follow-up was significantly smaller in the K-line (-) group (-11.8 \pm 10.4 degrees) than in the K-line $(+)$ group (10.2 \pm 12.1 degrees). Preoperative local kyphosis angle was significantly larger in the K-line (-) group (16.6 \pm 10.0 degrees) than in the K-line $(+)$ group (1.6 \pm 3.1 degrees). Local kyphosis angle at follow-up was significantly larger in the K-line $(-)$ group $(14.7 \pm 7.6$ degrees) than in the K-line $(+)$ group (1.3 \pm 3.1 degrees) (Table 2$)$. 
Table 2

Comparison between K-line $(-)$ and K-line $(+)$

\begin{tabular}{|llll|}
\hline & K-line(-) & K-line(+) & P \\
\hline Numbers of the patients & 11 & 57 & \\
\hline Age (years old) & $57.2 \pm 17.5$ & $60.9 \pm 11.0$ & NS \\
\hline The JOA score at preoperation (points) & $10.1 \pm 4.3$ & $9.7 \pm 2.6$ & NS \\
\hline The JOA score at follow-up (points) & $11.6 \pm 4.1$ & $13.3 \pm 2.2$ & $<0.01$ \\
\hline The RR of the JOA score (\%) & $19.4 \pm 25.2$ & $50.6 \pm 25.8$ & $<0.01$ \\
\hline C2-7angle at preoperation & $-10.1 \pm 9.0$ & $6.8 \pm 11.2$ & $<0.01$ \\
(degrees) & & & $<0.01$ \\
\hline C2-7angle at follow-up (degrees) & $-11.8 \pm 10.4$ & $10.2 \pm 12.1$ & $<01$ \\
\hline Local kyphosis angle & $16.6 \pm 10.0$ & $1.6 \pm 3.1$ & $<0.01$ \\
at preoperation (degree) & & & \\
\hline Local kyphosis angle at follow-up (degree) & $14.7 \pm 7.6$ & $1.3 \pm 3.1$ & $<0.01$ \\
\hline Data are presented as means \pm SD. & & & \\
\hline JOA: Japanese Orthopaedic Association & & & \\
\hline RR: recovery rate & & & \\
\hline
\end{tabular}

With follow-up, we found that 7 cases of preoperative K-line (-) changed to K-line (+) because of absorption of the protruded disc (disc type; Fig. 1). On the other hand, 4 cases of preoperative K-line (-) due to the osteophyte or the beak of local kyphosis still stayed as K-line (-) at follow-up (osseous type; Fig. 2). We compared the clinical data between disc type (Fig. 3) and osseous type as shown in Table 3. Mean RR in the K-line (-) group classified as disc type was $27.6 \%$ at follow-up (Fig. 3). On the other hand, mean RR in the K-line (-) group classified as osseous type was only 5.0\% (Fig. 2). This difference was statistically significant. 
Table 3

Characteristics of K-line $(-)$ patients by types

\begin{tabular}{|llll|}
\hline & Disc type & Osseous type & $\mathbf{p}$ \\
\hline Number & 7 & 4 & \\
\hline Age (yr) & $57.4 \pm 15.1$ & $56.8 \pm 23.9$ & NS \\
\hline Pre-JOA (points) & $11.1 \pm 3.1$ & $8.1 \pm 5.8$ & NS \\
\hline FU-JOA (points) & $13.4 \pm 1.6$ & $8.6 \pm 5.8$ & NS \\
\hline RR of JOA (\%) & $27.6 \pm 28.1$ & $5.0 \pm 10.0$ & $<0.05$ \\
\hline Pre-MRI C2-7angle (degrees) & $-6.0 \pm 7.4$ & $-17.3 \pm 7.1$ & $<0.05$ \\
\hline Fu-MRI C2-7angle (degrees) & $-6.7 \pm 4.5$ & $-20.8 \pm 12.3$ & $<0.05$ \\
\hline Data are presented as means \pm SD. & & \\
\hline JOA: Japanese Orthopaedic Association & & \\
\hline RR: recovery rate & & \\
\hline
\end{tabular}

\section{Discussion}

Surgical outcomes for CSM accompanying local kyphosis have generally been reported as less than acceptable. Baba et al. [11] reported that patients with preoperative kyphosis (mean angle of $11.7^{\circ}$ ) show significantly poorer neurological improvement.

Suda et al. [8] also reported that outcomes of LP for CSM accompanying local kyphosis with an angle exceeding 13 degrees (when coexisted with myelomalacia) and 5 degrees (without myelomalacia) were poorer than those for CSM without local kyphosis in their multivariate logistic regression analysis. In contrast, Kaptain et al. [12] and Uchida et al. [13] have shown that surgical outcomes were not correlated with preoperative cervical kyphosis. We speculated that their conclusion might have been due to the kyphosis in their patients being mild. Kasai and Uchida reported that the presence or absence of anterior or posterior subarachnoid space of the spinal cord in postoperative MRI correlated significantly with clinical outcome of LP [14]. The present study has indicated that K-line can be a factor to predict the clinical outcome of LP for CSM. That is, cases preoperatively defined as K-line (-) displayed poorer clinical outcome after LP compared to those defined K-line (+). In particular, this is the first report to show that the disc type for preoperative K-line (-), in which disc was absorbed during the follow-up and the classification changed into K-line (+) at follow-up, achieved better clinical outcomes compared to patients showing the osseous type. However, outcome for disc type were worse than those of K-line (+). Moreover, predicting whether the bulging disc will be resorbed after surgery in not currently possible. Miyamoto et al. [15] reported that posterior correction surgery for patients with CSM accompanied by local kyphosis resulted 
in a better clinical outcome than LP alone. Therefore, posterior correction surgery combined with LP should thus be considered for CSM in K-line (-) patients.

\section{Conclusion}

The present study has indicated that K-line can be a factor to predict the clinical outcome of LP for CSM. In K-line (-), the disc type showed somewhat better outcomes compared to the osseous type. However, the results were not sufficient. Therefore, posterior correction surgery combined with LP should be considered for CSM with K-line(-).

\section{Abbreviations}

LP: Laminoplasty; OPLL: posterior longitudinal ligament; CSM: cervical spondylotic myelopathy; JOA: The Japanese Orthopaedic Association; RR: recovery rate

\section{Declarations}

\section{Availability of data and materials}

The study was analyzed using data obtained from patients who provided informed consent.

\section{Ethics approval and consent to participate}

The study protocol was approved by the Institutional Review Board of Kindai University Hospital ( Control Cohort Study, No.2020-025). We conducted this study under approval of the institutional review board and informed consent was obtained from all patients. This study does not include patients under 18 years of age.

\section{Consent for publication}

Not applicable

\section{Competing interests}

The Authors declare that they have no competing interests.

\section{Funding}

The authoers declealre no potential conflict interest concerning this study.

\section{Authors' contributions}

TI collected the datas and interpreted, and wrote the manuscript. HM,MA contributed to design of the work and revised the manuscript critically for important content. All authors read and approved the final 
manuscript.

\section{Acknowledgments}

The authors would like to thank Dr. Koichiro Maeno for his help in collecting clinical data.

\section{References}

1. Hirabayashi K, Satomi K. Operative procedure and result of expansive open-door laminoplasty. Spine. 1988;13(7):870-6.

2. Hirabayashi K, Watanabe K, Wakano N, Suzuki N, Satomi K, Ishii Y. Expansive open-door laminoplasty for cervical spinal stenotic myelopathy. Spine. 1983;8(7):693-9.

3. Sodeyama T, Goto S, Mochizuki M, Takahashi J, Moriya H. Effect of decompression enlargement laminoplasty for posterior shifting of the spinal cord. Spine (Phila pa 1976). 1999;24(15):1527-31.

4. Iwasaki M, Okuda S, Miyauchi A, Sakaura H, Mukai Y, Yonenobu K, Yoshikawa H. Surgical strategy for cervical myelopathy due to ossification of the posterior longitudinal ligament: Part 1: Clinical results and limitations of laminoplasty. Spine. 2007;32(6):647-53.

5. Yamazaki A, Homma T, Uchiyama S, Katsumi Y, Okumura H. Morphologic limitations of posterior decompression by midsagittal splitting method for myelopathy caused by ossification of the posterior longitudinal ligament in the cervical spine. Spine. 1999;24(1):32-4.

6. Baba H, Uchida K, Maezawa Y, Furusawa N, Azuchi M, Imura S. Lordotic alignment and posterior migration of the spinal cord following en bloc open-door laminoplasty for cervical myelopathy: a magnetic resonance imaging study. J Neurol. 1996;243(9):626-32.

7. Fujiyoshi T, Yamazaki M, Kawabe J, Endou T, Furuya T, Koda M, Okawa A, Takahashi K, Konishi H. A new concept for making decisions regarding the surgical approach for cervical ossification of the posterior longitudinal ligament: the K-line. Spine. 2008;33(26):E990-3.

8. Suda K, Abumi K, Ito M, Shono Y, Kaneda K, Fujiya M. Local kyphosis reduces surgical outcomes of expansive open-door laminoplasty for cervical spondylotic myelopathy. Spine. 2003;28(12):125862.

9. Chiba K, Toyama Y, Watanabe M, Maruiwa H, Matsumoto M, Hirabayashi K. Impact of longitudinal distance of the cervical spine on the results of expansive open-door laminoplasty. Spine. 2000;25(22):2893-8.

10. Tomita K, Kawahara N, Toribatake Y, Heller JG. (1998) Expansive midline T-saw laminoplasty (modified spinous process-splitting) for the management of cervical myelopathy. Spine Jan 1;23(1):32-37.

11. Baba H, Maezawa Y, Furusawa N, imura S, Tomita K. Flexibility and alignment of the cervical spine after laminoplasty for spondylotic myelopathy. A radiographic study. Int orthop. 1995;19(2):116-21.

12. Kaptain GJ, Simmons NE, Replogle RE, Pobereskin L. Incidence and outcome of kyphotic deformity following laminectomy for cervical spondylotic myelopathy. J Neurosurg. 2000;93(2 suppl):199- 
204.

13. Uchida K, Nakajima H, Sato R, Yayama T, Mwaka ES, Kobayashi S, Baba H. Cervical spondylotic myelopathy associated with kyphosis or sagittal sigmoid aliment: outocome after anterior or posterior decompression. J neurosug Spine. 2009;11(5):521-8.

14. Kasai $Y$, Uchida A. New evaluation method using preoperative magnetic resonance imaging for cervical spondylotic myelopathy. Arch Orthop Trauma Surg. 2001;Oct(9):508-10. 121.

15. Miyamoto H, Maeno K, Uno K, Kakutani K, Nishida K, Sumi M. Outcomes of surgical intervention for cervical spondylotic myelopathy accompanying local kyphosis (comparison between laminoplasty alone and posterior reconstruction surgery using the screw-rod system). Eur Spine J. 2014;23(2):341-34.

\section{Figures}

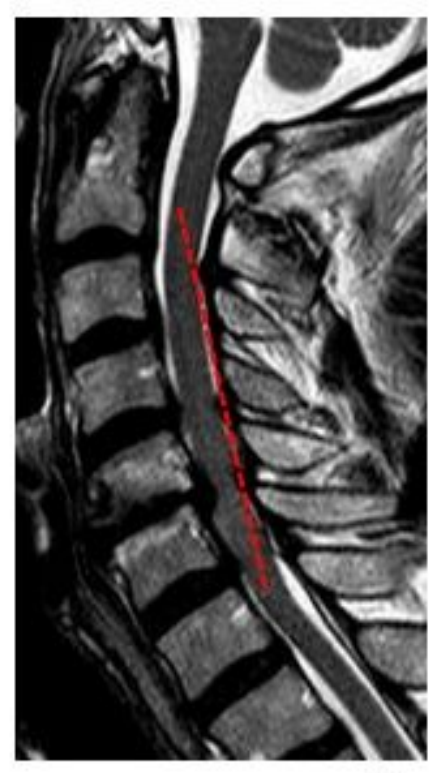

A

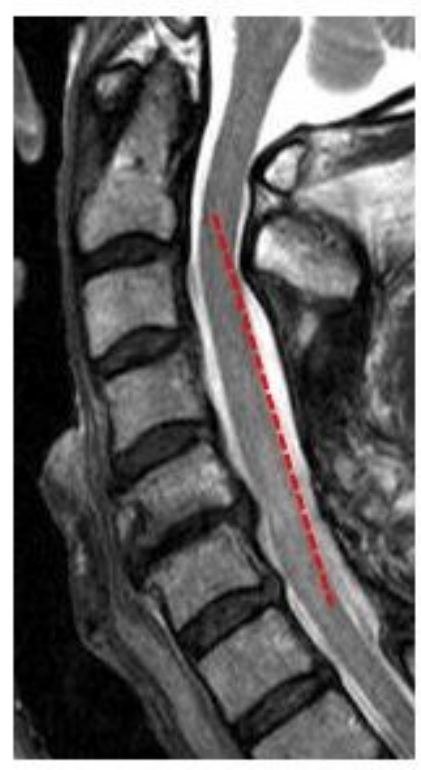

B

\section{Figure 1}

69-year-old male with K-line (+). Laminoplasty was performed from C3 to C7. C2/C7 angle was $29^{\circ}$ at preoperation $(A)$ and $28^{\circ}$ at follow-up (B). The JOA score improved from 13 points to 15.5 points. The recovery rate of the $\mathrm{JOA}$ score was $62.5 \%$. 

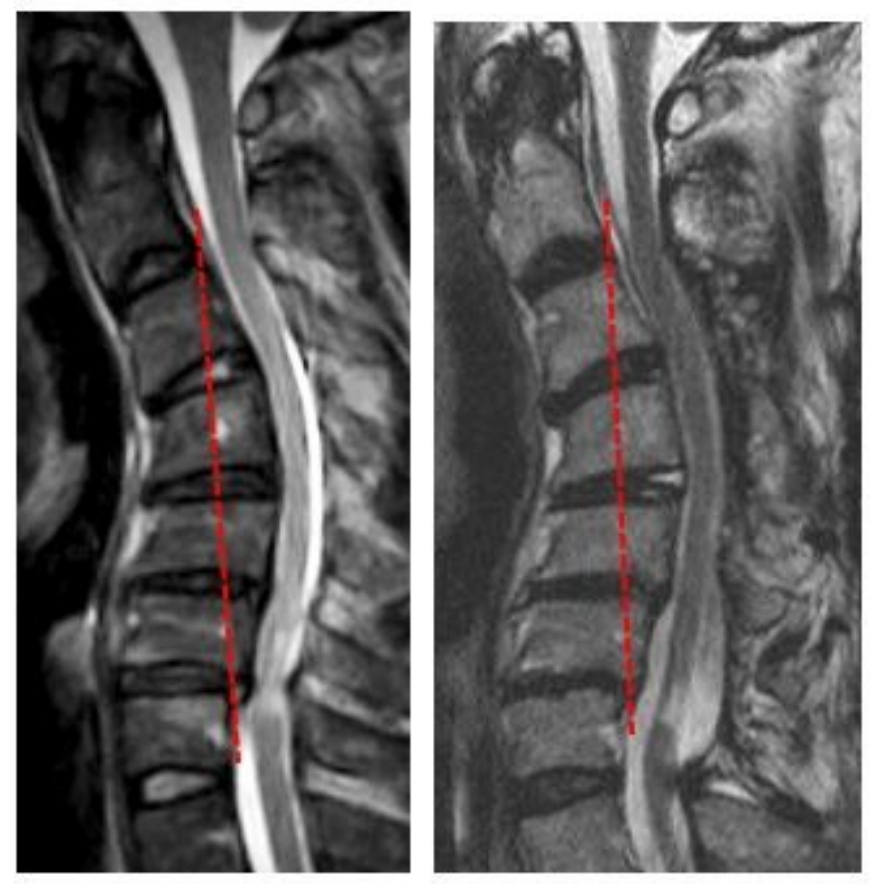

A

B

Figure 2

44-year-old male with K-line (-). Laminoplasty was performed from C3 to C7. C2/C7 angle was $-39^{\circ}$ at preoperation (A) and $-39^{\circ}$ at follow-up (B). The JOA score improved from 7 points to 9 points. The recovery rate of the JOA was $20 \%$.

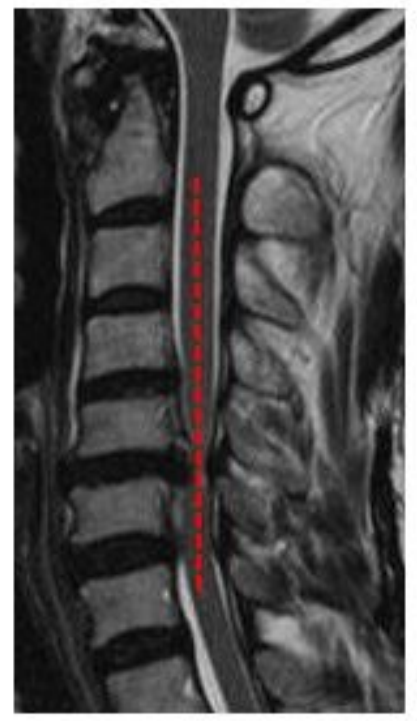

A

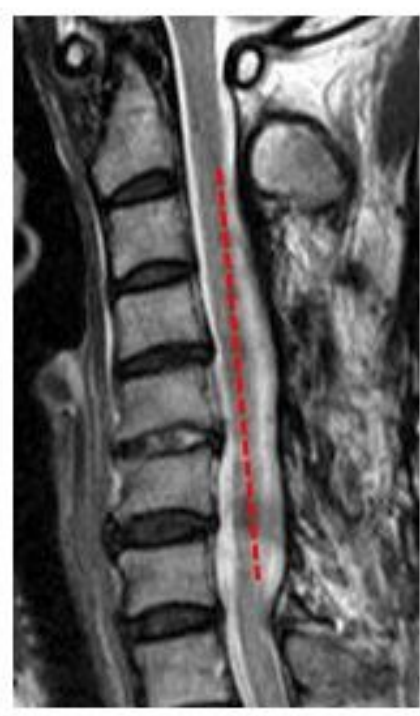

B

\section{Figure 3}

50-year-old female with $\mathrm{K}$-line (-). Laminoplasty was performed from $\mathrm{C} 3$ to $\mathrm{C} 7$. $\mathrm{C} 2 / \mathrm{C} 7$ angle was $-1^{\circ}$ at preoperation (A) and $-16^{\circ}$ at follow-up (B). The JOA improved from 11 points to 13.5 points. The recovery 
rate of the JOA score was $41.7 \%$. The protruded disc at $\mathrm{C} 5 / 6$ had a contact with $\mathrm{K}$-line at preoperation (A). However, at the follow-up (B), the disc was absorbed, and the classification was changed to K-line (+). 